\title{
Development of New Concept Vehicles Using Modelica and Expectation to Modelica from Automotive Industries
}

\author{
Yutaka Hirano \\ Toyota Motor Corporation, Future Project Division \\ 1200 Mishuku, Susono, Shizuoka, 410-1193 JAPAN \\ yutaka@hirano.tec.toyota.co.jp
}

\begin{abstract}
Recently development of new-concept small vehicles for future mobility societies becomes very active. In this paper, development of simulation models of those new vehicles by Modelica is described. It became clear that such small vehicles tend to have reduced stability and handling ability than conventional vehicles. To cope with this problem, a benchmark study of designing vehicle control logic for an IWM (InWheel-Motor) vehicle was settled by Japanese society of automotive industries and academia. A brief description about this benchmark study is also given. At the end, requests to Modelica community from Japanese automotive industries are described.
\end{abstract}

Keywords: Future mobility vehicles; Stability and Handling Performance; Benchmark study

\section{Introduction}

To cope with future mobility society, development of many new concept vehicles is becoming increasingly active in recent years [1]. Those vehicles have characteristics of smaller size, lighter weight, less number of passengers than the conventional vehicles. Also those vehicles tend to be equipped with lower RRC (Rolling Resistance Coefficients) tires and new driving systems mainly using electric motors to achieve less emission and less energy consumption. Some of those future vehicles are equipped with IWM (In-WheelMotor) systems to achieve flexible layout of powertrain and also advanced vehicle motion control [2]. Because such new-concept vehicles have different mechanical structure and control structure from those of conventional cars, it was necessary to make new models to estimate their motions by simulation. In this paper, development of the simulation models of those new vehicles by Modelica is described. Those models were developed based on Vehicle Dynamics Library (VDL) of Dymola.

By the simulation, it became clear that such new small vehicles tend to have reduced stability and handling ability than conventional vehicles. To cope with this problem, a benchmark study of improving stability and handling ability of such new vehicles was settled by Japanese joint committee of automotive industries and academia. As a member of the committee, the author will introduce the benchmark study in this paper.

At the end of this paper, some requests from Japanese automotive industries to Modelica community are described. Those requests came from actual problem which was encountered by the users during the modeling and simulation works for new mobility vehicles.

\section{Modeling and simulation of future vehicles}

\subsection{Target vehicles}

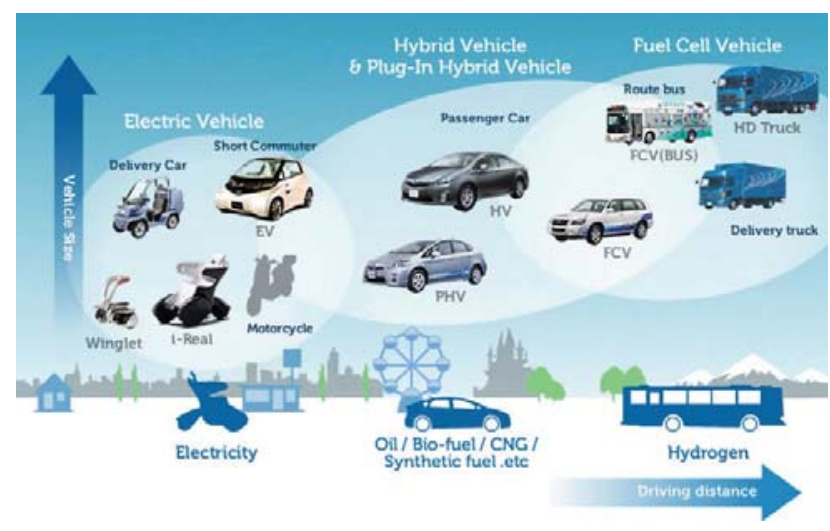

Figure 1: Toyota's scenario about future eco-cars 
Figure 1 shows Toyota's broad scenario about future eco-vehicles. As shown in the Figure, electric vehicles are thought suitable as future mobility for short distance. Those vehicles often have different structure from conventional cars. Thus it is necessary to make new models for new kinematics and control to simulate the motion of those new vehicles. In this paper, simulation models of a personal mobility 'i-Real' and a 'short commuter' by Modelica are described.

\subsection{Simulation of a personal mobility 'i-Real'}

Figure 2 shows a photograph of Toyota's proto-type personal mobility called 'i-Real'. It has two front wheels and one rear wheel. Steering system is equipped with the rear wheel. The rear wheel is connected by a swing arm with the body and it is possible to change the length of wheel-base by controlling the angle of the swing arm actively. There are electric inwheel-motors for each front wheel and rotation speed of each wheel can be controlled independently. Also there is a link to control the height of each front wheels independently. Thus, it is possible to control roll angle of the vehicle body against the ground actively.

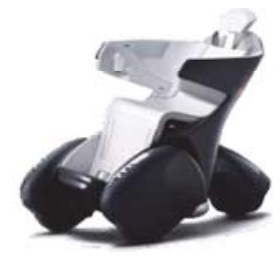

Figure 2: Personal mobility 'i-Real'

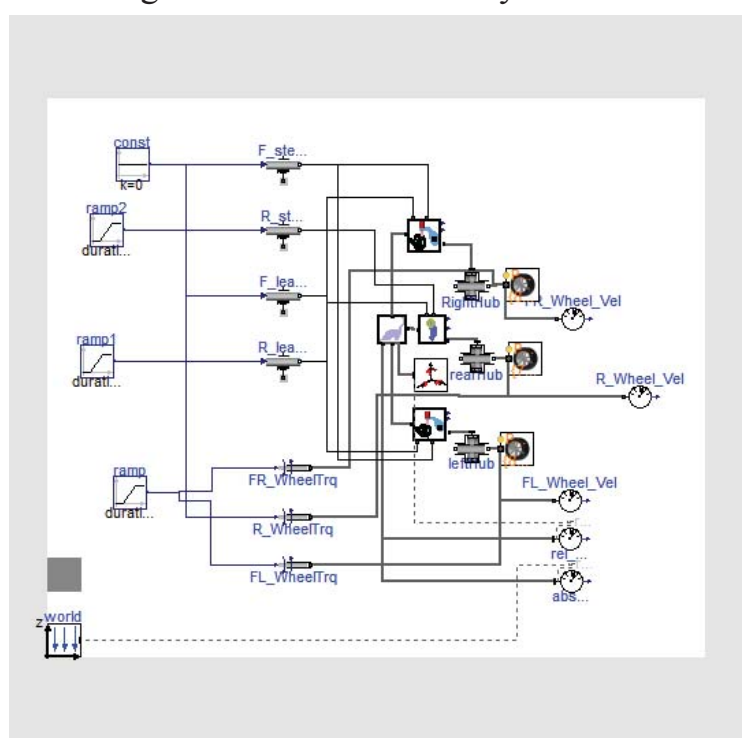

Figure 3: Dymola model of 'i-Real'
Figure 3 shows Dymola model of the mechanical structure of ' $i$-Real'. Each mechanical part is constructed by using Multi-Body-Systems (MBS) library and connected with the models of tires and environment of Vehicle Dynamics Library (VDL).

Figure 4 shows an animation result comparing a case when active control of wheel-base and roll angle was applied and a case when no control was applied while cornering. Figure 5 shows time plots of vehicle speed, lateral acceleration and yaw rate in this case. It was successful to simulate the effect of active roll-angle control and wheelbase control. Basic design of the vehicle motion controller was made upon this simulation model.

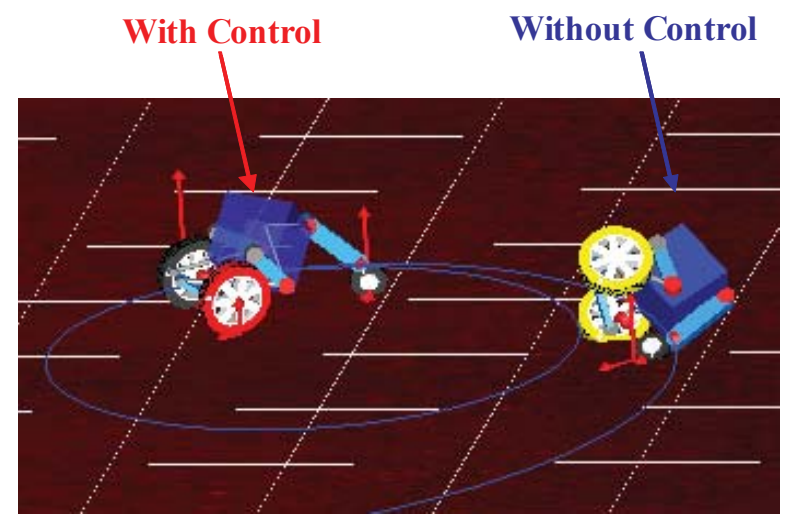

Figure 4: Simulation result animation of 'i-Real' 


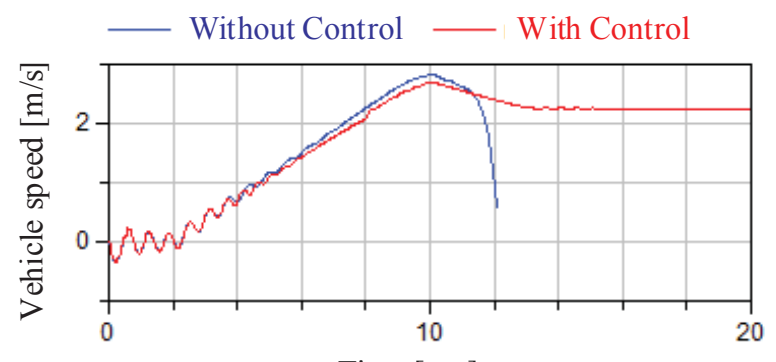

Time [sec]
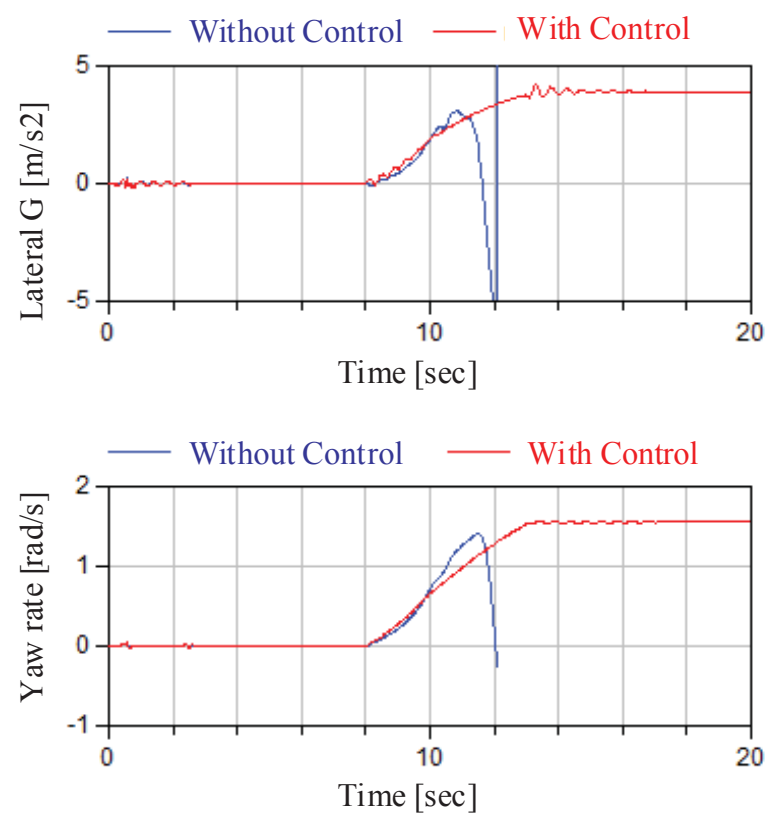

Figure 5: Time plots of 'i-Real' simulation

\subsection{Simulation of a 'short commuter' vehicle}

\subsubsection{Background and purpose}

Recently many small vehicles for short running distance mainly for the usage in a city area are proposed. Though, as shown in Figure6, lighter vehicle weight and smaller vehicle size tend to result in decreased resistance against external disturbances such as sidewind. Also tires having low RRC tend to have reduced side stiffness as compared to normal tires. Thus it is expected that handling performance of such small and light vehicles equipped with low RRC tires tend to be affected more than conventional vehicles.

To confirm this expectation, simulation of side wind test for both a conventional vehicle and a short commuter vehicle was executed. As an example of the short commuter vehicle, a small vehicle in which two passengers ride in series on the center of the vehicle was assumed. The specifications of both the short commuter vehicle and a conventional vehicle are shown in Table 1.

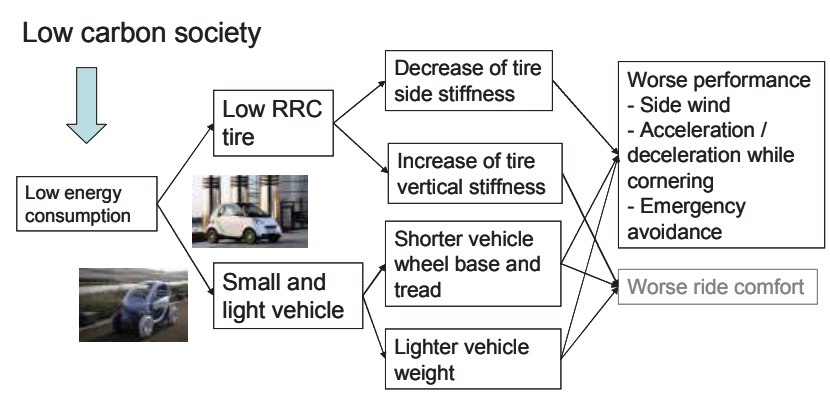

Figure 6: Problems for small commuter vehicles

Table 1: Specifications of vehicles

\begin{tabular}{|c|c|c|}
\hline & $\begin{array}{l}\text { Short commuter } \\
\text { vehicle }\end{array}$ & $\begin{array}{l}\text { Conventional } \\
\text { vehicle }\end{array}$ \\
\hline Weight & $510 \mathrm{~kg}$ & $1300 \mathrm{~kg}$ \\
\hline Wheel Base & $2000 \mathrm{~mm}$ & $2600 \mathrm{~mm}$ \\
\hline Width & $1190 \mathrm{~mm}$ & $1760 \mathrm{~mm}$ \\
\hline Height & $1460 \mathrm{~mm}$ & $1515 \mathrm{~mm}$ \\
\hline
\end{tabular}

Vehicles run across a zone of side wind of $20 \mathrm{~m} / \mathrm{s}$ while running at $60 \mathrm{~km} / \mathrm{h}$. Figure 7 shows the result of an animation for the open-loop side wind test, i.e. there is no control about steering. It is evident that the short commuter vehicle is affected a lot than the conventional vehicle by the side wind.

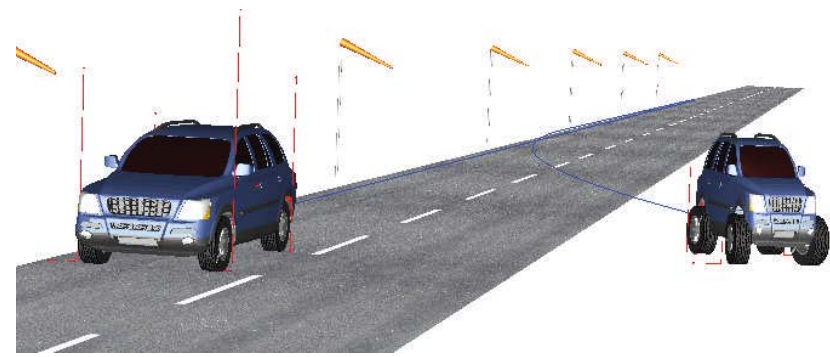

Figure 7: Result animation of side-wind test

Upon above backgrounds, it is planned to study about designing a control system for a future small IWM vehicle. The system enables control of individual steering angle and camber angle of each wheel as well as driving / braking torque of each wheel. The purpose of the study is to design a controller of an IWM vehicle to realize same level of handling and stability performance as conventional vehicles satisfy- 
ing minimum energy consumption of IWMs simultaneously. This problem is announced to the wide area of academia as one of the benchmark studies from the automotive industries by joint committee of JSAE (Society of Automotive Engineers of Japan) and SICE (Society of Instrument and Control Engineers) about 'vehicle modeling and control research' in Japan. Anyone who wishes to join this benchmark study can freely obtain the model library from the web site below. The evaluation functions of the benchmark results will also be provided from the web site.

(http://cig.ees.kyushuu.ac.jp/benchmark JSAE_SICE/)

\subsubsection{Structure of the simulation model}

Figure 8 shows a whole structure of the simulation model based on VDL of Dymola. The model consists of a vehicle model and a driver model. The vehicle model includes 3D multi-body dynamics model of body and suspension. It is possible to control steering angle and camber angle of each wheel independently. The control of steering angle and camber angle of each wheel is realized by changing independently the length of two parallel lower arms of a double wishbone suspension which has an upper A-arm [3] as shown in Figure 8. Also a simple electric model of battery and IWM is included to calculate energy consumption of IWMs. There is a simple battery model which considers inner resistance and constant voltage generation. Electricity is provided to each DC motor and the motor converts electric current to driving / braking torque of each wheel by the following equation.

$$
\tau_{i}=K_{m} \times i_{i} \quad(i=1 \cdots 4)
$$

where $\tau_{i}$ : Motor torque, $K_{m}$ : Constant, $i_{i}$ : Motor current .

Power consumption of each motor is calculated by a multiplication of battery voltage and current flowing into the each motor.

There also is a model of driver's behavior which calculates commands for steering angle, acceleration pedal, braking pedal and so on. The driver model consists of function blocks of perception, planning and tracking respectively. The perception block calculates current vehicle status (position, speed, angle, etc.). The planning block settles target points on the path to be followed on the road from the information of the perception block. The tracking block calculates driver's maneuver commands for steering, acceleration pedal, brake pedal and so on. These commands are transferred to the vehicle model to calculate the vehicle motion.

Finally all the models necessary for the simulation were integrated in one model library. Also test cases of desired tasks mentioned below were included in the library.

\subsubsection{Description of desired tasks}

The limitation of actuators of each wheel is shown in Table 2. There is no limitation for driving and braking torques of each IWM, but the requirement of minimizing energy consumption of IWMs is applied. The energy to control steering angle and camber angle of each wheel is not considered.

Table 2: limits of actuators for each wheel

\begin{tabular}{|l|l|}
\hline Actuator & Limit \\
\hline Steering angle & $\begin{array}{c}30 \text { degrees (Front tires) } \\
5 \text { degrees (Rear tires) }\end{array}$ \\
\hline Camber angle & 10 degrees (All tires) \\
\hline
\end{tabular}

Four test scenarios were used for the benchmark study as below.

1) Acceleration while cornering on low friction road:

Accelerate the vehicle from initial speed $0[\mathrm{~km} / \mathrm{h}]$ to $70[\mathrm{~km} / \mathrm{h}]$ in 5 seconds on a slippery (coefficient of friction $(\mathrm{mu})=0.6)$ curve of $\mathrm{R}=50[\mathrm{~m}]$ as shown in Figure 9.

2) Deceleration while cornering on a sprit friction road:

Decelerate the vehicle from initial speed $70[\mathrm{~km} / \mathrm{h}]$ to $0[\mathrm{~km} / \mathrm{h}]$ in 5 seconds on a slippery split $\mathrm{mu} \quad(\mathrm{mu}=$ $\{0.9,0.4\})$ curve of $\mathrm{R}=50[\mathrm{~m}]$ as shown in Figure 10.

3) Double lane change:

Perform ISO double lane change task at the speed of $70[\mathrm{~km} / \mathrm{h}]$.

4) Crossing side wind:

Run straight while crossing strong side wind at the speed of $70[\mathrm{~km} / \mathrm{h}]$. 


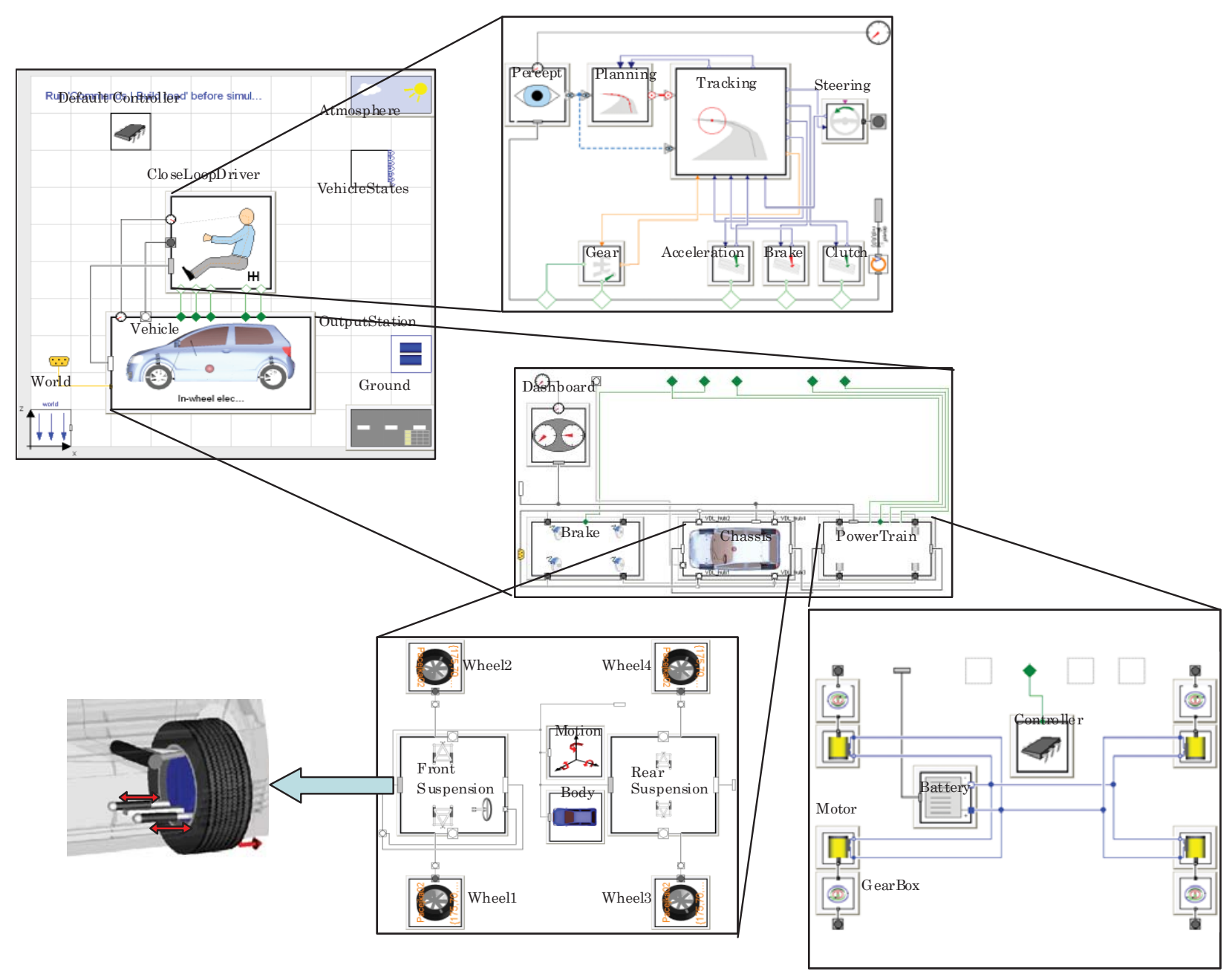

Figure 8: Diagram of main layers of the simulation model 


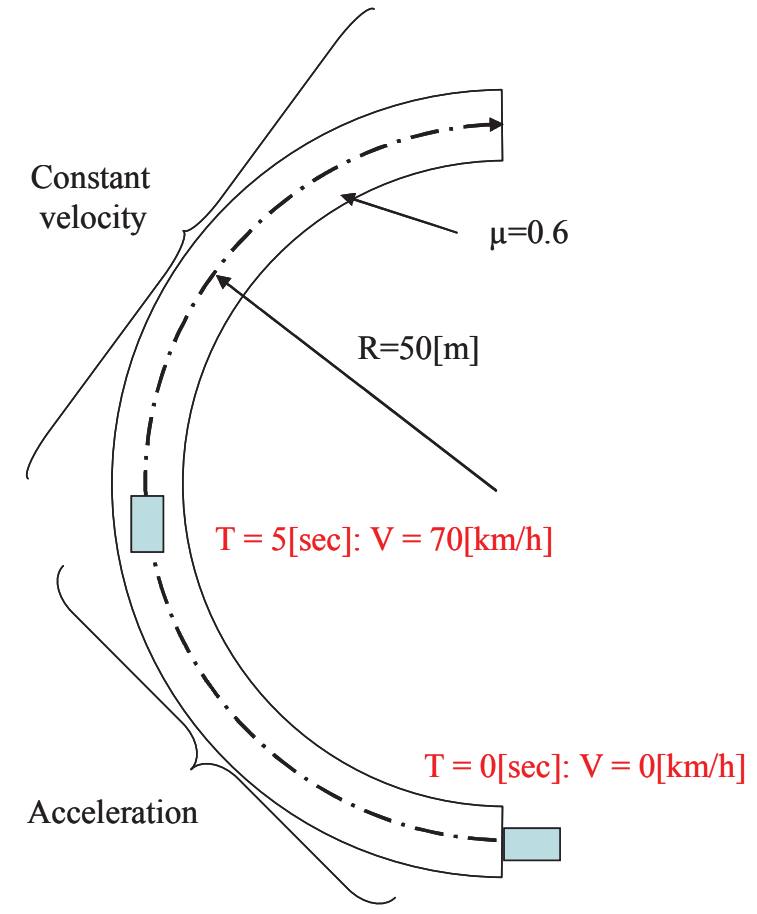

Figure 9: Test condition for 'acceleration while cornering' task

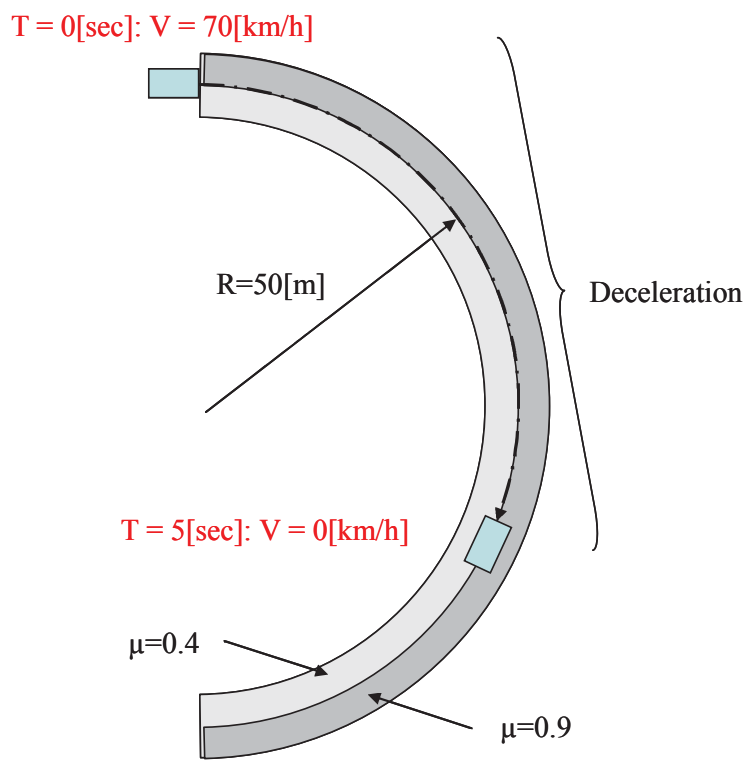

Figure 10: Test condition for 'deceleration while cornering' task

\subsubsection{Vehicle model}

As shown in Figure 8, the vehicle model consists of sub-models of brake, chassis and power train. Inside the chassis model, multi-body dynamics of suspension links and joints are considered. Figure 11 shows Dymola model of the new suspension with two lower arms for which their length are actively controlled to control the camber angle and steering angle of the wheel independently. Also body motion is considered by multi-body dynamics model which has inputs from each suspension linkage. Because of this, the effects to body motion by suspension geometries such as anti-dive geometry, anti-squat geometry and so on can be considered. About tire model, 'magic formula model' (Pacejka'02) [4] is used.

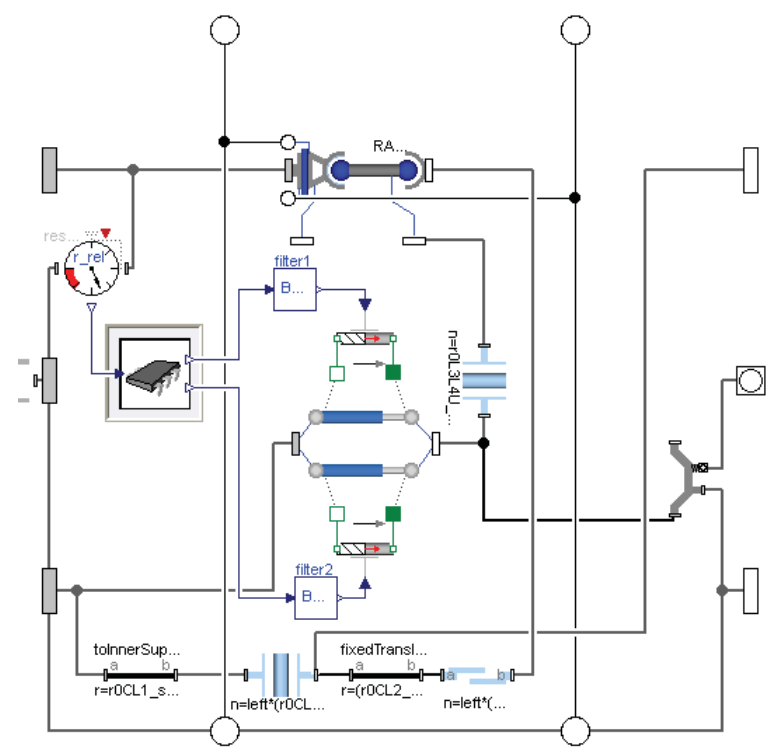

Figure 11: Dymola model of the new suspension

\subsubsection{Driver model}

Desired path and desired position of the vehicle on the path (target points) are settled on the road respectively according to the desired road shape and the vehicle speed profile for each task. 'Planning' block of the driver model shown in Figure 8 arranges target points along the desired path considering a preview distance of the driver model. 'Tracking' block calculates commands for steering angle, acceleration pedal angle and braking force respectively using the information from 'Planning' block and 'Perception' block. Each command is calculated as follows.

Steering angle command: str_cmd

$$
\text { str_cmd }=\tan ^{-1}\left(\frac{r V_{-} x}{r V_{-} y}\right) * s t r_{-} g a i n+s t r_{-} \text {offset }
$$

where 
$r V \_x$ : longitudinal distance along path between target point and current vehicle position,

$r V_{-} y$ : lateral distance along path between target point and current vehicle position,

str gain: steering gain,

str offset: offset value (optional).

Acceleration pedal command: $a c c \_c m d$

$$
a c c \_c m d=K_{a c c} \times D
$$

and

Braking force command: $b r k \_c m d$

$$
\text { brk_cmd }=-K_{b r k} \times D
$$

where

$K_{a c c}$ : Proportional gain for acceleration command, and

$K_{b r k}$ : Proportional gain for braking command,

$$
\begin{aligned}
& D=K\left(v V_{-} P_{-} x-v_{-} v e h\right) \\
& +\frac{K N s}{T_{d} s+N}\left(v V_{-} P_{-} x-v_{-} v e h\right) \\
& +\frac{K}{T_{i} s}\left(v V_{-} P_{-} x-v_{-} v e h\right)
\end{aligned}
$$

Here,

$K$ : Proportional feedback gain

$T_{d}$ : Inverse of differential feedback gain

$T_{i}$ : Inverse of integral feedback gain

$N$ : Constant

$s$ : Laplace operator

$v V_{-} P_{-} x$ : Reference velocity along path

v_veh: Vehicle velocity along path

\subsubsection{Controller model}

To provide a template of controller model, an example model of the controller (default controller) is also provided in the model library. It is required for researchers of this benchmark study to propose revisions to the default controller (and also driver model if necessary) to realize the following demands.

1) Let vehicle yaw rate, side slip angle and lateral acceleration follow the desired values (ideal motion of conventional vehicle) and / or make a deviation from desired path to minimum under limitation of control amounts of steering angle and camber angle of each wheel.

2) Minimize energy consumption of IWMs.

The desired yaw rate, the desired slip angle and the desired lateral acceleration are calculated as bellows.

Desired slip angle:

$$
\beta_{\text {ref }}=0
$$

Desired yaw rate:

$$
\gamma_{\text {ref }}=\frac{K_{s}}{1+s T_{s}} \delta_{\text {input }}
$$

Desired lateral acceleration:

$$
G_{y_{-} \text {ref }}=V \times \gamma_{\text {ref }}
$$

Here, $K_{s}$ and $T_{s}$ are settled from the desirable motion of the conventional vehicle as follows.

$$
\begin{aligned}
K_{s} & =\frac{\left(a_{f}+a_{r}\right) c_{f} c_{r} V}{a_{r} c_{r} M V^{2}+a_{f}\left(a_{f}+a_{r}\right) c_{f} c_{r}} \\
T_{s} & =\frac{M a_{f} V}{\left(a_{f}+a_{r}\right) c_{f}}
\end{aligned}
$$

Here, following parameters are selected as a nominal value of the conventional vehicle for

$a_{f}$ : Longitudinal distance between front wheel and CG (Centre of gravity)

$a_{r}$ : Longitudinal distance between rear wheel and $\mathrm{CG}$

$c_{f}$ : Cornering stiffness of front two tyres

$c_{r}$ : Cornering stiffness of rear two tyres

$M$ : Mass of vehicle

$V$ : Vehicle speed.

As a tentative example, the default controller calculates commands for the actuators as bellows.

Front steering angle:

$$
\delta_{i}=s t r \_c m d / G_{s}(i=1,2)
$$

$\left(G_{s}\right.$ : Virtual steering gear ratio)

Rear steering angle:

$$
\delta_{i}=0 \quad(i=3,4)
$$

Camber angle of all wheels:

$$
\alpha_{i}=0 \quad(i=1 \sim 4)
$$

Driving / braking torque:

$$
\begin{aligned}
& \tau_{i}=K_{\text {torque }} \cdot\left(a c c \_c m d \quad \text { or } \quad b r k_{-} c m d\right) \\
& +K_{p} \cdot\left(V_{\text {ref }}-V\right)+K_{i} \cdot \int\left(V_{\text {ref }}-V\right) d t
\end{aligned}
$$

where

$$
\begin{aligned}
& K_{\text {torque }}: \text { Constant } \\
& K_{p}: \text { Proportional feedback gain } \\
& K_{i}: \text { Integral feedback gain } \\
& V_{\text {ref }}: \text { Desired vehicle speed }
\end{aligned}
$$




\subsubsection{Tentative results of an example}

As a tentative example, a result of applying the default controller in the case of 'deceleration while cornering' task is shown below. Figure 12 shows a time plot of vehicle speed. Only by above default controls it was not possible to trace the desired trajectory as shown in Figure 13. Figure 14 shows a time plot of side slip angle of both the cars in this case. Author now encourages many academic people to join this benchmark study.

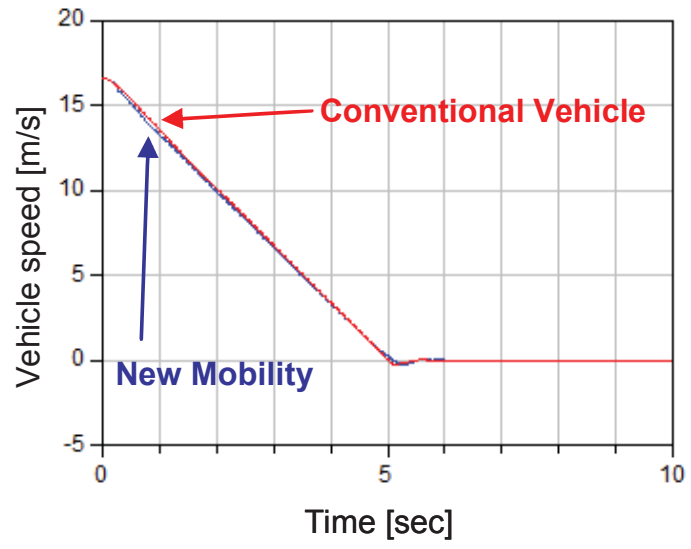

Figure 12: Vehicle speed of conventional vehicle and new mobility for deceleration while cornering' task

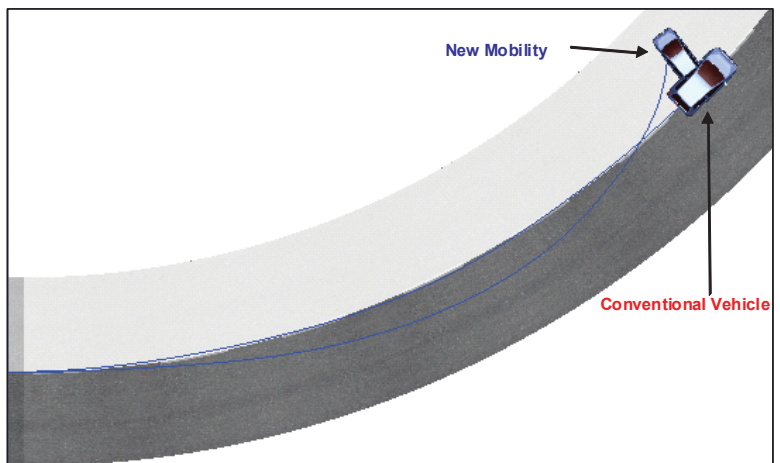

Figure 13: Trajectories of conventional vehicle and new mobility for 'deceleration while cornering' task

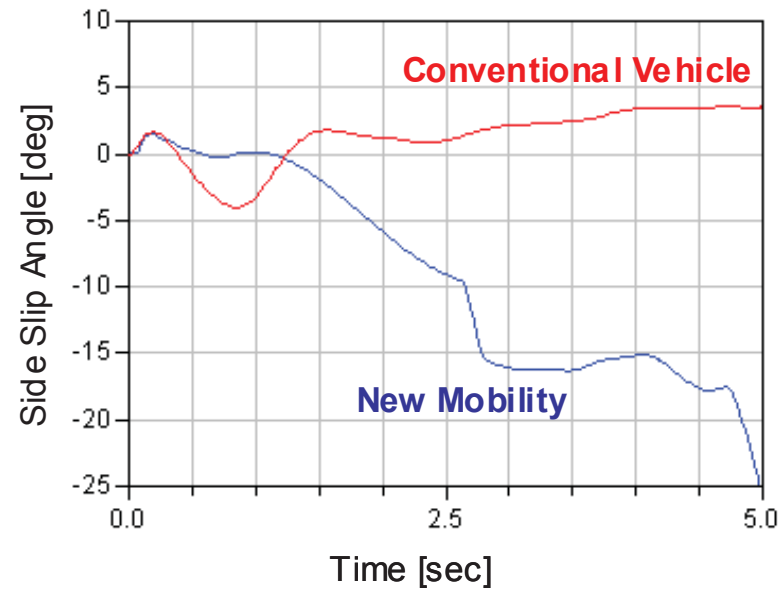

Figure 14: Vehicle slip angle of conventional vehicle and new mobility for 'deceleration while cornering' task

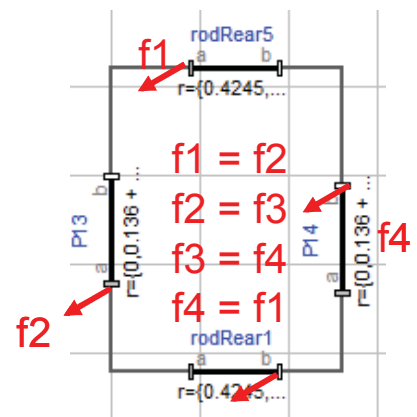

f3

Figure 15: Limitation of calculating rigid mechanical loop of rigid elements by Modelica

\section{Requests to Modelica from Japa- nese automotive industries}

In the way of developing Dymola models for automotive applications, there occurred many requests to Modelca community from automotive industries. Table 3 summarizes the requests, though there are some ambiguous points and further discussion seems necessary. It is highly appreciated that Modelica Association will consider those requests in future development of Modelica specification, Modelica tools and also in future activity about Modelica. For this purpose, there is a high expectation to the activity of MIAB (Modelica Industrial Advisory Board).

As for the request number 21, the author will give an additional explanation. This request relates to a demand to convert CAD model to Modelica model di- 
rectly. There often are cases of making a rigid structure by combining rigid elements when making mechanical structure models by CAD. However, by current limitation of Modelica, it is impossible to calculate such models because the force and torque acting on the every edge of the rigid elements are over constrained as shown in Figure 15. It is highly desired that such limitation will be removed in the future.

\section{Conclusions}

For some future mobility vehicles, Modelica models were developed for many virtual tests by the simulation. It was proved that such simulations were useful to estimate the motion of new mechanisms and also the effect of controls before making actual vehicles. To cope with the one of the potential problem of the future small-size vehicles, a benchmark study was proposed by Japanese committee of automotive industries and academia. It is highly welcome that many control researchers will join and challenge to the benchmark study. An organized session of this benchmark study will be held in coming IFAC-AAC (Advances in Automotive Control) 2013 symposium which will be held in September of 2013 in Japan.

\section{Acknowledgement}

Development of the model library for the benchmark study was done by close cooperation with Modelon $\mathrm{AB}$.

\section{References}

[1] Gombert B., "eCorner - the electric propulsion system of the future", Proceeding of Chassis Tech Plus 2011, pp. 803-813, 2011.

[2] Katsuyama E., "Decoupled 3-D moment control by an In-Wheel Motor vehicle" Proceeding of Chassis Tech Plus 2011, pp. 133-150, 2010.

[3] Andreasson J. : On Generic Road Vehicle Motion Modeling and Control, Doctoral thesis KTH (Royal Institute of Technology, Sweden), Aeronautical and Vehicle Engineering, Trita-AVE, ISSN 1651-7660; 2006:85,2006.

[4] Pacejka H.B., Tyre and Vehicle Dynamics, 2002, Butterworth-Heinemann, ISBN 07506 $5121-5$

[5] Ito H., Ohata A., Butts K. : Equation-Based Model Data Structure for High Level Physical Modeling, Model Simplification and Modelica-Export, 4th International Workshop on Equation-Based Object-Oriented Modeling Languages and Tools. September, 2011, ETH Z"urich, Switzerland 
Table 3: Requests from Japanese automotive industries to Modelica

\begin{tabular}{|c|c|c|}
\hline Issue & No. & Requests \\
\hline Readability of model & 1 & $\begin{array}{l}\text { Improve readability of a model by avoiding difference between text-based } \\
\text { description and GUI (connection editor) based description. (It's possible to } \\
\text { write a model such that the parts are not connected in GUI but connected in } \\
\text { text layer. ) For example, making a guideline about the way of description } \\
\text { for the definition of connection. }\end{array}$ \\
\hline \multirow[t]{3}{*}{ Code generation } & 2 & Support C code generation for best-fit to compiler's optimization. \\
\hline & 3 & $\begin{array}{l}\text { Improve readability of generated } \mathrm{C} \text { codes so that the modification by hand } \\
\text { coding will be easier. }\end{array}$ \\
\hline & & $\begin{array}{l}\text { Support C code generation for paraller processing. For example, specifying } \\
\text { the importance of calculation causality between different physical domain } \\
\text { and if the importance is small, then enable code generation so that the } \\
\text { different domain can be calculated }\end{array}$ \\
\hline \multirow[t]{2}{*}{ Units } & 5 & Support the unit of [rpm]. \\
\hline & 6 & $\begin{array}{l}\text { Categorize and claasify physical domain of SI units more clearly. (There } \\
\text { are too many SI unit domains to search easily now.) }\end{array}$ \\
\hline \multirow[t]{6}{*}{ Libraries } & 7 & $\begin{array}{l}\text { Increase library blocks to connect different domains. ( For example, } \\
\text { between translational domain and rotational domain ) }\end{array}$ \\
\hline & 8 & Increase Modelica standard libraries \\
\hline & 9 & $\begin{array}{l}\text { Develop libraries for interaction of heat flow and mechanical systems } \\
\text { (combustion engine, friction, damper, etc.) }\end{array}$ \\
\hline & 10 & $\begin{array}{l}\text { Develop libraries for interaction between mechanical vibration and sound } \\
\text { field analysis. }\end{array}$ \\
\hline & 11 & Develop libraries to simplify 3D flow anaysis simulation to 1D flow \\
\hline & 12 & To make commercial library independent for different modelica-based \\
\hline Error handling & 13 & Improve the traceability of the reason of a error. \\
\hline \multirow[t]{5}{*}{ Usability } & 14 & Make arbitrary one model class replacable by simple GUI. \\
\hline & 15 & $\begin{array}{l}\text { Make it possible to specify physical variables to be shown in the simulation } \\
\text { results (hopefully by simple GUI). }\end{array}$ \\
\hline & 16 & Support revision management function for model classes and package files. \\
\hline & 17 & $\begin{array}{l}\text { Enable error handling and variables monitoring for protected models. (For } \\
\text { example, models from suppliers.) }\end{array}$ \\
\hline & 18 & $\begin{array}{l}\text { Enhance FMI compatiblity to other tools (Ex. GT-SUITES, CarMaker, } \\
\text { CarSim, Star-CD, etc.) }\end{array}$ \\
\hline \multirow[t]{3}{*}{ Modeling methodology } & 19 & $\begin{array}{l}\text { Support of a new modeling methodorogy based on conservation laws of } \\
\text { physical systems. (As HLMD from Toyota [5].) }\end{array}$ \\
\hline & 20 & $\begin{array}{l}\text { Model reduction: } \\
\text { 1) Simplify precise equation-bassed physical models by numerical } \\
\text { sensitivity analysis (ex. Sparce handling). } \\
\text { 2) Identify parameters for non-linear dynamic parametric models from } \\
\text { experimental data. }\end{array}$ \\
\hline & 2 & Let the calculation for kinematic loops of rigid bodies possible. \\
\hline
\end{tabular}

